\title{
TEORI KONSTRUKTIVISTIK PADA PEMBELAJARAN LUAS BANGUN DATAR
}

\author{
Suyoto $^{1)}$, Mita Hapsari Jannah ${ }^{2)}$ \\ ${ }^{1)}$ PGSD/FKIP, Universitas Muhammadiyah Purworejo \\ ${ }^{2)}$ Pendidikan Matematika/FKIP, Universitas Muhammadiyah Purworejo \\ Email: yoto.suyoto84@yahoo.com ${ }^{1)}$; mita_umpwr@protonmail.com ${ }^{2}$
}

\begin{abstract}
This study aimed to determine: (a) how the learning process of plane based on constructivistic learning theory; and (b) the effectiveness of such learning in improving learning achievement. The subject of this study was all of $5^{\text {th }}$ class of SD Negeri Purworejo. Data analysis technique in this study included qualitative descriptive technique, quantitative descriptive and quantitative t-test. After the preliminary analysis it was found that this constructivistic learning was done with multimedia Powerpoint, greenboard, and pencil-paper. Based on the field note and the observation of two teachers it was found that learning has been done according to constructivist learning theory. Teacher's response questionnaire generated a score of 39.5, as well as the t-test yielded $t_{\text {count }}=2.016>1.645=t_{\text {table }}$. This means that learning based on constructivist learning theory was significantly effective to improve learning achievement.
\end{abstract}

Keywords: constructivistic, multimedia, plane

\section{PENDAHULUAN}

Berdasarkan observasi di tiga SD di Purworejo didapatkan bahwa siswa masih banyak yang belum paham asalusul rumus luas bangun datar. Mereka juga tidak tahu bahwa luas persegi bisa didapatkan dari dua kali luas segitiga. Ini berarti siswa masih terbiasa dengan hafalan tanpa ada konstruksi pemahaman.

Faktor konstruksi pemahaman pada siswa merupakan salah satu faktor internal yang mempengaruhi prestasi belajar. Faktor konstruksi pemahaman ini adalah faktor yang muncul pada diri seorang siswa itu sendiri.

Teori

konstruktivistik menekankan bahwa belajar yang baik berasal dari prakarsa siswa. Muijs dan Reynolds (2008: 97) menjelaskan bahwa siswa adalah konstruktor pengetahuan aktif yang memiliki sejumlah konsekuensi yaitu: a) Belajar selalu merupakan sebuah proses aktif; b) Anak-anak belajar paling baik dengan menyelesaikan berbagai konflik kognitif (konflik dengan berbagai ide dan prakonsepsi lain) melalui pengalaman, refleksi dan metakognisi; c) Bagi konstruktivis, belajar adalah pencarian makna; d) Konstruksi pengetahuan bukan sesuatu yang bersifat individual semata tetapi juga dikonstruksikan secara sosial, melalui interaksi dengan teman sebaya, guru, orang tua, dan sebagainya; e) Elemen lain yang berakar pada fakta bahwa siswa secara individual dan kolektif mengkonstruksikan pengetahuan; f) Belajar selalu dikonseptualisasikan dalam hubungannya dengan apa yang telah kita ketahui; g) Belajar secara betul-betul mendalam berarti mengkonstruksikan pengetahuan secara menyeluruh, dengan mengeksplorasi dan menengok kembali materi yang kita 
pelajari dan bukan dengan cepat pindah satu topik ke topik lain; dan h) Mengajar adalah tentang memberdayakan pelajar, dan memungkinkan pelajar untuk menemukakan dan melakukan refleksi terhadap pengalaman-pengelaman realistis. Ini juga membuat kaum konstruktivis percaya bahwa lebih baik menggunakan bahan-bahan hands-on daripada textbook.

Pandangan konstruktivistik telah mempengaruhi perkembangan multimedia interaktif. Pandangan konstruktivistik percaya bahwa metode pembelajaran latihan dan praktik (drill and practice), kurang mampu mengembangkan pebelajar sepanjang hayat. Hal ini berarti metode belajar tersebut sulit untuk diterapkan pada situasi baru. Dalam pengembangan multimedia pembelajaran, teori konstruktivistik menganjurkan metode hypermedia, simulasi, dan lain-lain yang lebih bermanfaat bagi siswa. Dengan metode tersebut siswa bebas mencari informasi, menerapkan gaya belajar mereka sendiri, dan menggunakan perangkat lunak sebagai sumber belajar selain guru.

Media perangkat lunak komputer dalam pembelajaran menurut Rusman (2012: 153) merupakan program pembelajaran yang digunakan dalam proses pembelajaran dengan menggunakan software komputer (CD Pembelajaran) berupa program omputer yang berisi tentang muatan pembelajaran, meliputi: judul, tujuan, materi pembelajaran, dan evaluasi pembelajaran. Media komputer bisa dikatakan media tercanggih untuk saat ini. Program yang mudah dan sering dipakai adalah Ms Powerpoint yang dikembangkan dari tahun 1984 (Muttappallymyalil, 2016) hingga versi terbaru tahun 2016.
Sebelum media komputer berkembang, digunakanlah media papan tulis (board). Mulai dari blackboard, green/brown board, lalu ke whiteboard. Media ini lebih efisien daripada media komputer dari sisi biaya pengadaan. Karenanya media ini masih banyak dijumpai di sekolah-sekolah di Indonesia. Khusus greenboard, media ini dikembangkan akhir tahun 1960an (Muttappallymyalil, 2016). Greenboard memiliki keunggulan lebih awet dan permukaannya lebih halus daripada blackboard. Greenboard juga lebih memudahkan guru atau siswa untuk menggambar diagram dan bangunbangun matematis daripada whiteboard karena alat tulisnya yang menggunakan kapur alih-alih spidol.

Masih menurut Muttappallymyalil (2016), guru dapat menggunakan teknologi media yang paling canggih dengan tetap tidak melupakan prinsipprinsip pendidikan. Artinya apa yang mudah bagi guru maupun siswa sebagai media, itu yang harus diutamakan, sehingga media yang paling mutakhir saat ini dapat menjadi bagian komprehensif dari sistem pendidikan.

Senada dengan itu, Arsyad (2013: 74) menyatakan bahwa ada beberapa kriteria yang perlu diperhatikan dalam pemilihan media pembelajaran. Yakni: a) sesuai dengan tujuan yang ingin dicapai; b) tepat untuk mendukung isi pelajaran; c) praktis, luwes, dan bertahan; d) keterampilan guru dalam menggunakannya; e) pengelompokan sasaran; serta f) mutu teknis.

Berdasarkan dua pendapat di atas, maka pembelajaran bermedia komputer dikembangkan dengan tidak lupa mempertimbangkan media konvensional yang sudah ada sebelumnya di sekolah, misalnya greenboard. Hal ini agar mempermudah guru dan siswa dalam penggunaannya. 
Berdasarkan pada ketiga hal tersebut di atas, yaitu pembelajaran luas bangun datar, fakta adanya teori belajar kontruktivistik, serta penggunaan multimedia, maka penting diadakan suatu pembelajaran luas bangun datar yang didasarkan pada teori belajar kontruktivistik berbantukan multimedia.

Tujuan penelitian ini adalah untuk mengetahui: (a) bagaimana proses pembelajaran materi luas bangun datar berbasis teori belajar konstruktivistik; serta (b) keefektivan pembelajaran tersebut dalam meningkatkan prestasi belajar.

\section{METODE PENELITIAN}

Metode penelitian ini adalah metode gabungan kualitatif dan kuantitatif. Data diambil melalui wawancara, observasi, angket respon, dan tes. Teknik analisis data yang digunakan adalah teknik deskripsi kualitatif, deskripsi kuantitatif, dan uji-t (Sugiyono, 2011).

Penelitian dilaksanakan di SD Negeri Purworejo pada bulan Maret sampai Juli 2017. Subjek penelitian adalah siswa kelas V SD. Sedangkan objek penelitian adalah bagaimana proses pembelajaran materi luas bangun datar berbasis teori belajar konstruktivistik; serta keefektivan pembelajaran tersebut dalam meningkatkan prestasi belajar.

Secara ringkas penjelasan tahapan penelitian beserta teknik pengambilan data dan teknik analisis data yang digunakan disajikan pada Tabel 1 di bawah.

Dari Tabel 1, dikatakan pembelajaran luas bangun datar dengan teori belajar konstruktivistik ketika memenuhi dua kondisi berikut. a) hasil angket respon guru mempunyai skor lebih dari 25; dan b) uji- $t$ menunjukkan $t_{\text {hitung }}>t_{\text {tabel }}$ sehingga $\mathrm{H}_{0}$ ditolak. Artinya prestasi kelas eksperimen yang menggunakan teori belajar konstruktivistik lebih baik daripada prestasi kelas kontrol yang konvensional.

Tabel 1. Tahap Penelitian

\begin{tabular}{|c|l|l|l|}
\hline Tahap & \multicolumn{1}{|c|}{ Kegiatan } & \multicolumn{1}{|c|}{$\begin{array}{c}\text { Teknik Pengambilan } \\
\text { Data }\end{array}$} & \multicolumn{1}{|c|}{$\begin{array}{c}\text { Teknik } \\
\text { Analisis } \\
\text { Data }\end{array}$} \\
\hline Pendahuluan & $\begin{array}{l}\text { Analisis teori belajar konstruktivistik, } \\
\text { analisis kurikulum, serta analisis } \\
\text { kebutuhan guru dan siswa }\end{array}$ & $\begin{array}{l}\text { Wawancara tak terstruktur } \\
\text { serta observasi dengan } \\
\text { catatan lapangan }\end{array}$ & $\begin{array}{l}\text { Deskriptif } \\
\text { kualitatif }\end{array}$ \\
\hline $\begin{array}{c}\text { Perancangan } \\
\text { Materi }\end{array}$ & $\begin{array}{l}\text { Merancang materi berdasarkan analisis } \\
\text { pendahuluan tahap sebelumnya }\end{array}$ & $\begin{array}{l}\text { Refleksi diri dengan } \\
\text { observasi }\end{array}$ & $\begin{array}{l}\text { Deskriptif } \\
\text { kualitatif }\end{array}$ \\
\hline Pembelajaran & $\begin{array}{l}\text { Pembelajaran dilaksanakan untuk 30 } \\
\text { siswa kelas eksperimen dan 30 siswa } \\
\text { kelas kontrol. Lembar observasi } \\
\text { dibagikan kepada 2 orang guru untuk } \\
\text { menilai jalannya pembelajaran } \\
\text { berdasarkan teori konstruktivistik di } \\
\text { kelas eksperimen. }\end{array}$ & $\begin{array}{l}\text { Observasi dengan catatan } \\
\text { lapangan servasi }\end{array}$ & $\begin{array}{l}\text { Deskriptif } \\
\text { kualitatif }\end{array}$ \\
\hline Uji Keefektivan & $\begin{array}{l}\text { Pengisian angket respon oleh 2 orang } \\
\text { guru serta pengambilan data prestasi } \\
\text { sebagai perbandingan antara kelas } \\
\text { eksperimen dengan kelas kontrol. }\end{array}$ & $\begin{array}{l}\text { Angket respon guru dan } \\
\text { tes prestasi }\end{array}$ & $\begin{array}{l}\text { Deskriptif } \\
\text { kuantitatif } \\
\text { dan analisis } \\
\text { kuantitatif } \\
\text { dengan uji- } t\end{array}$ \\
\hline
\end{tabular}


ISSN 2089-8703 (Print) Vol. 6, No. 3 (2017)

ISSN 2442-5419 (Online)

HASIL PENELITIAN DAN
PEMBAHASAN
Tahap Pendahuluan

Pada tahap ini dilakukan analisis teori belajar konstruktivistik, analisis kurikulum, serta analisis kebutuhan guru dan siswa. Analisis teori belajar konstruktivistik dilakukan dengan studi literature tentang teori-teori belajar konstruktivistik dan penerapannya dalam pembelajaran.

Tabel 2. Jenjang Materi Bangun Datar Pada Sekolah Dasar

\begin{tabular}{|c|c|c|c|c|}
\hline & & $\begin{array}{l}\text { Standar } \\
\text { Kompetensi }\end{array}$ & t & Mengenal bangun datar sederhana \\
\hline $\begin{array}{c}\text { Kelas I } \\
\text { Semester } 2\end{array}$ & $\begin{array}{l}\text { Tema Budi } \\
\text { Pekerti }\end{array}$ & $\begin{array}{l}\text { Kompetensi } \\
\text { Dasar }\end{array}$ & t & $\begin{array}{l}\text { - Menunjukkan benda-benda yang secara geometris } \\
\text { berbentuk segitiga, segiempat dan lingkaran. } \\
\text { - Menyebutkan ciri-ciri segitiga, segiempat, dan } \\
\text { lingkaran ditinjau dari banyak sisinya. } \\
\text { - Menjiplak berbagai bentuk segitiga, segiempat, dan } \\
\text { lingkaran. } \\
\text { - Mengelompokkan berbagai bentuk segitiga, } \\
\text { segiempat, dan lingkaran, menurut bentuk, } \\
\text { permukaan, warna, atau ciri lainnya. }\end{array}$ \\
\hline \multirow{2}{*}{$\begin{array}{l}\text { Kelas II } \\
\text { Semester } 2\end{array}$} & \multirow{2}{*}{$\begin{array}{c}\text { Tema } \\
\text { Lingkungan }\end{array}$} & $\begin{array}{l}\text { Standar } \\
\text { Kompetensi }\end{array}$ & & Mengenal unsur-unsur bangun datar sederhana \\
\hline & & $\begin{array}{l}\text { Kompetensi } \\
\text { Dasar }\end{array}$ & : & $\begin{array}{l}\text { - Mengelompokkan bangun datar. } \\
\text { - Mengenal sudut bangun datar }\end{array}$ \\
\hline \multirow{4}{*}{$\begin{array}{l}\text { Kelas III } \\
\text { Semester } 2\end{array}$} & \multirow{2}{*}{$\begin{array}{l}\text { Tema } \\
\text { Kerajinan } \\
\text { Tangan; } \\
\text { Kegemaran }\end{array}$} & $\begin{array}{l}\text { Standar } \\
\text { Kompetensi }\end{array}$ & . & Memahami unsur dan sifat-sifat bangun datar sederhana \\
\hline & & $\begin{array}{l}\text { Kompetensi } \\
\text { Dasar }\end{array}$ & : & $\begin{array}{l}\text { - Mengidentifikasi berbagai bangun datar sederhana } \\
\text { menurut sifat atau unsurnya } \\
\text { - Mengidentikasi berbagai jenis dan besar sudut }\end{array}$ \\
\hline & \multirow[b]{2}{*}{$\begin{array}{c}\text { Tema } \\
\text { Pendidikan }\end{array}$} & $\begin{array}{l}\text { Standar } \\
\text { Kompetensi }\end{array}$ & & $\begin{array}{l}\text { Menghitung keliling, luas persegi dan persegi panjang, } \\
\text { serta penggunaannya dalam pemecahan masalah }\end{array}$ \\
\hline & & $\begin{array}{l}\text { Kompetensi } \\
\text { Dasar }\end{array}$ & : & $\begin{array}{l}\text { - Menghitung keliling persegi dan persegi panjang } \\
\text { - Menghitung luas persegi dan persegi panjang } \\
\text { - Menyelesaikan masalah yang berkaitan dengan } \\
\text { keliling, luas persegi dan persegi panjang }\end{array}$ \\
\hline \multirow[b]{2}{*}{$\begin{array}{l}\text { Kelas IV } \\
\text { Semester } 1\end{array}$} & & $\begin{array}{l}\text { Standar } \\
\text { Kompetensi }\end{array}$ & & $\begin{array}{l}\text { Menggunakan konsep keliling dan luas bangun datar } \\
\text { sederhana dalam pemecahan masalah }\end{array}$ \\
\hline & & $\begin{array}{l}\text { Kompetensi } \\
\text { Dasar }\end{array}$ & & $\begin{array}{l}\text { - Menentukan keliling dan luas jajar genjang dan } \\
\text { segitiga } \\
\text { - Menyelesaikan masalah yang berkaitan dengan } \\
\text { keliling dan luas jajar genjang dan segitiga }\end{array}$ \\
\hline \multirow[b]{2}{*}{$\begin{array}{l}\text { Kelas IV } \\
\text { Semester } 2\end{array}$} & & $\begin{array}{l}\text { Standar } \\
\text { Kompetensi }\end{array}$ & & $\begin{array}{l}\text { Memahami sifat bangun ruang sederhana dan hubungan } \\
\text { antar bangun datar }\end{array}$ \\
\hline & & $\begin{array}{l}\text { Kompetensi } \\
\text { Dasar }\end{array}$ & & $\begin{array}{l}\text { - Mengidentifikasi benda-benda dan bangun datar } \\
\text { simetris. } \\
\text { - Menentukan hasil pencerminan suatu bangun datar. }\end{array}$ \\
\hline \multirow{2}{*}{$\begin{array}{l}\text { Kelas V } \\
\text { Semester } 1\end{array}$} & & $\begin{array}{l}\text { Standar } \\
\text { Kompetensi }\end{array}$ & & $\begin{array}{l}\text { Menghitung luas bangun datar sederhana dan } \\
\text { menggunakannya dalam pemecahan masalah }\end{array}$ \\
\hline & & $\begin{array}{l}\text { Kompetensi } \\
\text { Dasar }\end{array}$ & & $\begin{array}{l}\text { - Menghitung luas trapesium dan layang-layang } \\
\text { - Menyelesaikan masalah yang berkaitan dengan luas }\end{array}$ \\
\hline
\end{tabular}


ISSN 2089-8703 (Print) Vol. 6, No. 3 (2017)

ISSN 2442-5419 (Online)

\begin{tabular}{|c|l|l|l|l|}
\hline & & & bangun datar \\
\hline & & $\begin{array}{l}\text { Standar } \\
\text { Kompetensi }\end{array}$ & $:$ & $\begin{array}{l}\text { Memahami sifat-sifat bangun dan hubungan antar } \\
\text { bangun }\end{array}$ \\
\cline { 3 - 4 } $\begin{array}{c}\text { Kelas V } \\
\text { Semester 2 }\end{array}$ & $\begin{array}{l}\text { Kompetensi } \\
\text { Dasar }\end{array}$ & $:$ & $\begin{array}{l}\bullet \text { Mengidentifikasi sifat-sifat bangun datar } \\
\text { Menyelidiki sifat-sifat kesebangunan dan simetri } \\
\text { Menyelesaikan masalah yang berkaitan dengan } \\
\text { bangun datar sederhana }\end{array}$ \\
\hline
\end{tabular}

Dari analisis kebutuhan guru dan siswa juga didapatkan bahwa guru dan siswa sudah terbiasa menggunakan media powerpoint. Karenanya untuk kemudahan penggunaan, pembelajaran menggunakan multimedia powerpoint. Mengingat bahwa komputer untuk tiap anak tidak tersedia di dalam kelas, tetapi hanya di laboratorium komputer, maka penggunaan media powerpoint dikombinasikan dengan greenboard/papan tulis. Pengombinasian ini oleh guru juga mempermudah siswa dalam mengonstruksi luas bangun datar agar bisa dipraktikkan langsung dengan pensil dan kertas.

\section{Tahap Perancangan Materi}

Pada tahap ini dirancang materi dengan multimedia Microsoft. PowerPoint 2007. Dari Tabel 2 di atas, dengan masukan guru dan mengingat kebutuhan siswa, maka diputuskan materi yang digunakan pada multimedia ini adalah materi bagun datar segitiga, persegi, persegi panjang, trapesium, jajargenjang, dan layang-layang. Pembahasan meliputi luas enam bangun datar tersebut.

Diharapkan dari konstruksi luas bangun datar, siswa juga semakin paham pengertian, ciri-ciri, sifat, dan hubungan antar bangun datar. Pemahaman ini akan nampak ketika siswa mengerjakan latihan soal, kuis 1 , dan kuis 2 (tes prestasi).

Meskipun program Microsoft. PowerPoint 2007 sudah dikenal oleh guru dan siswa, akan tetapi penggunaannya belum optimal dan menarik. Agar optimal, program ini dirancang sesuai teori belajar konstruktivistik, yakni memancing siswa untuk membangun pemahaman mereka sendiri. Baik ketika siswa sendiri yang menjalankan program tersebut maupun ketika guru yang menjalankan program tersebut untuk mengarahkan siswa.

Agar menarik, program ini dirancang menjadi multimedia. Yakni tidak hanya presentasi berupa tulisan, tapi juga animasi dan suara. Media yang digunakan juga tidak hanya powerpoint tapi dibantu oleh papan tulis (ketika guru presentasi) dan pensil-kertas (ketika siswa mengonstruksi pemahamannya).

Alasan lain pemilihan program Ms. PowerPoint yang sudah dikenal oleh guru adalah agar ke depannya sesuai perkembangan teknologi guru juga bisa mengembangkan sendiri program ini agar semakin optimal dan menarik. Misalnya powerpoint dapat diubah/convert menjadi flash dengan animasi yang lebih beragam sehingga kemasannya lebih menarik.

\section{Tahap Pembelajaran}

Pada tahap ini dilakukan pembelajaran berbasis teori belajar konstruktivistik pada 30 siswa kelas eksperimen. Untuk keperluan pengukuran efektivitas, dilakukan pembelajaran konvensional pada 30 siswa kelas kontrol. Gambaran pelaksanaannya sebagaimana Gambar 1, 2, dan 3 berikut. 


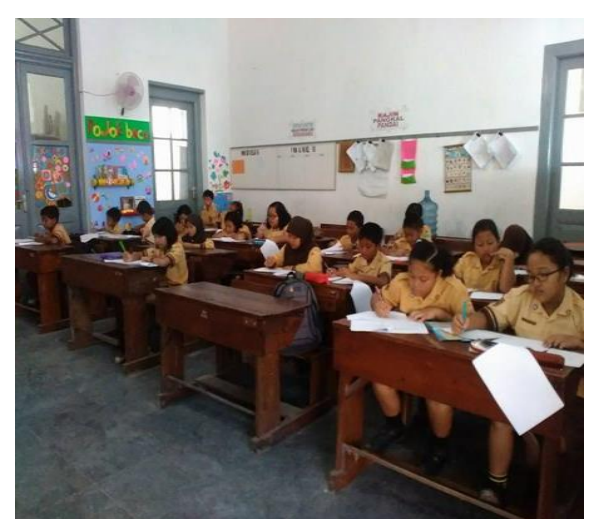

Gambar 1. Pembelajaran di Kelas Kontrol

Pembelajaran di kelas kontrol menggunakan pembelajaran konvensional. Yakni guru yang menjadi pusat pembelajaran. Guru menerangkan, langsung member rumus, lalu latihan soal. Sedangkan siswa hanya mendengar dan ditunutu untuk menghafal rumus agar dapat mengerjakan latihan soal.

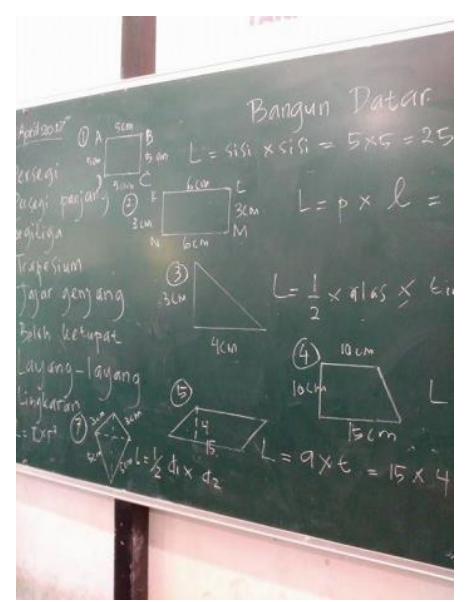

Gambar 2. Pembelajaran dengan Greenboard

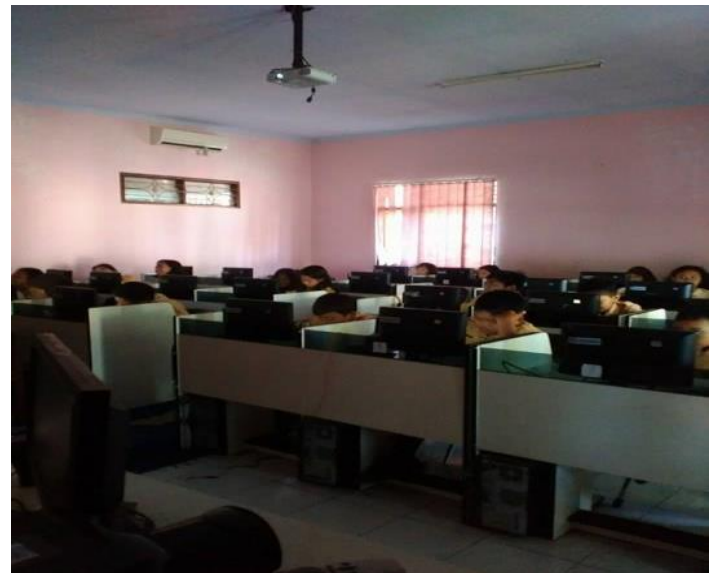

Gambar 3. Siswa Mengonstruksi

Sendiri Konsep Luas Bangun Datar

Sedangkan pada kelas eksperimen siswa mengonstruksi pemahaman bangun datar mereka sendiri. Untuk memudahkan penggunaan multimedia, tetap digunakan greenboard dan pensilkertas. Karena konstruksi rumus luas bangun datar tentunya tidak bisa sekali jadi. Gambar 4 berikut menggambarkan salah satu konstruksi rumus, yakni rumus luas trapesium.

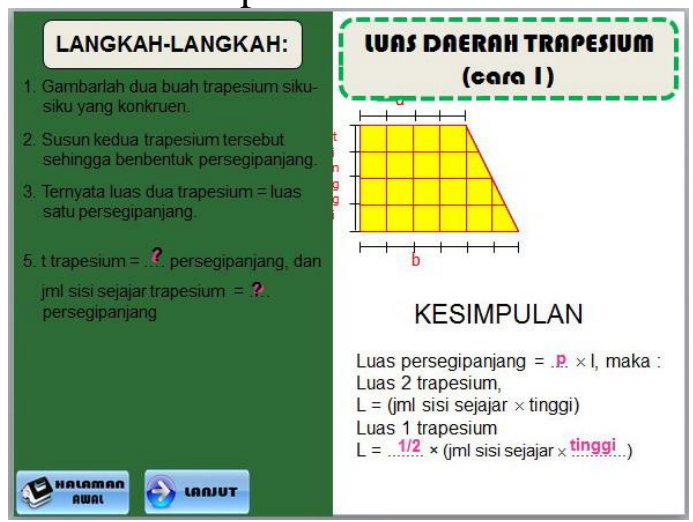

Gambar 4. Konstruksi Rumus Luas Trapesium

Pelaksanaan pembelajaran di kelas eksperimen diamati oleh 2 orang guru kelas V. Mereka berpendapat bahwa pembelajaran telah sesuai dengan teori belajar konstruktivistik.

\section{Tahap Uji Keefektivan}

Dilakukan uji keefektivan dengan dua teknik. Pertama, teknik angket, yakni dengan membagikan angket respon guru. Kedua adalah teknik tes. 
Hasil angket respon guru dapat dilihat pada Tabel 3 berikut. Dari dua orang guru, didapatkan skor 39.5. Artinya hasil angket respon guru mempunyai skor lebih dari 25. Hal ini bermaksud pembelajaran dengan teori belajar konstruktivistik dianggap efektif oleh guru.

Selanjutnya, teknik tes dilaksanakan dengan pemberian Kuis 2 . Dilakukan perbandingan data tes prestasi belajar dengan kelas kontrol. Hasil perbandingan diperoleh $t_{\text {hitung }}=$ 2.016 dengan $t_{\text {tabel }}=1.645$, sehingga uji- $t$ menunjukkan $t_{\text {hitung }}>t_{\text {tabel }}$ atau $\mathrm{H}_{0}$ ditolak. Artinya prestasi kelas eksperimen yang menggunakan pembelajaran berbasis teori konstruktivistik lebih baik daripada prestasi kelas kontrol yang menggunakan pembelajaran konvensional. Hal ini juga berarti penggunaan multimedia berbasis teori belajar konstruktivistik secara signifikan efektif terhadap peningkatan prestasi belajar siswa.

Tabel 3. Hasil Angket Respon Guru

\begin{tabular}{|c|c|c|}
\hline No & Pernyataan & Skor \\
\hline 1 & $\begin{array}{l}\text { Guru suka dengan pembelajaran berbasis teori belajar } \\
\text { konstruktivistik }\end{array}$ & 3 \\
\hline 2 & Waktu pembelajaran dapat dimanfaatkan dengan baik & 2.5 \\
\hline 3 & Pembelajaran berbasis teori belajar konstruktivistik berguna & 3 \\
\hline 4 & $\begin{array}{l}\text { Guru dapat memahami pengetahuan tentang pembelajaran berbasis } \\
\text { teori belajar konstruktivistik }\end{array}$ & 2.5 \\
\hline 5 & $\begin{array}{l}\text { Pembelajaran berbasis teori belajar konstruktivistik berpotensi } \\
\text { untuk mengonstruksi pemahaman peserta didik mengenai luas } \\
\text { bangun datar }\end{array}$ & 3 \\
\hline 6 & $\begin{array}{l}\text { Pembelajaran berbasis teori belajar konstruktivistik berpotensi } \\
\text { untuk mengembangkan aktivitas dan kreativitas peserta didik }\end{array}$ & 3 \\
\hline 7 & $\begin{array}{l}\text { Pembelajaran berbasis teori belajar konstruktivistik berpotensi } \\
\text { untuk mengembangkan motivasi peserta didik }\end{array}$ & 3 \\
\hline 8 & $\begin{array}{l}\text { Pembelajaran berbasis teori belajar konstruktivistik berpotensi } \\
\text { untuk menciptakan pembelajaran yang berpusat pada peserta didik }\end{array}$ & 3 \\
\hline 9 & Multimedia Powerpoint mudah digunakan & 2.5 \\
\hline 10 & Multimedia Powerpoint berguna bagi guru dan siswa & 2.5 \\
\hline 11 & Latihan soal disusun berdasarkan teori belajar konstruktivistik & 2.5 \\
\hline 12 & Kuis 1 dan kuis 2 benar-benar menguji pemahaman siswa & 3 \\
\hline 13 & Peserta didik mempunyai tujuan dalam belajar & 3 \\
\hline \multirow[t]{2}{*}{14} & $\begin{array}{l}\text { Guru menggunakan multimedia Powerpoint sebagai tujuan yang } \\
\text { ingin dicapai (sesuai dengan prinsip-prinsip belajar } \\
\text { konstruktivistik) }\end{array}$ & 3 \\
\hline & TOTAL SKOR & 39.5 \\
\hline
\end{tabular}

\section{Pembahasan}

Penelitian ini adalah penelitian pengembangan pembelajaran luas bangun datar berdasarkan teori belajar konstruktivistik. Hal ini sesuai dengan kesimpulan penelitian Sopamena (2009: 
99) bahwa konstruktivisme dapat menjadi kekuatan dalam membantu guru dalam pembelajaran matematika, terutama dalam mengembangkan strategi belajar matematika secara tepat.

Pada penelitian ini didapatkan bahwa pembelajaran dibantu oleh multimedia digital, yakni Powerpoint, serta multimedia konvensional, yakni greenboard dan pensil-kertas. Hal ini sesuai dengan kebutuhan siswa serta kemudahan penggunaan media dan konstruksi materi. Perpaduan multimedia digital dan konvensional juga disarankan oleh Muttappallymyalil (2016) agar media yang paling mutakhir saat ini dapat menjadi bagian komprehensif dari sistem pendidikan.

Pada akhirnya, yang diinginkan oleh pendidik adalah proses pembelajaran yang signifikan dalam meningkatkan prestasi belajar siswa. Penelitian ini telah berhasil menciptakan proses pembelajaran luas bangun datar berdasarkan teori belajar konstruktivistik berbantuan multimedia yang efektif secara signifikan dalam meningkatkan prestasi belajar siswa. Hal ini sejalan dengan hasil penelitian Widiyasari (2015: 64-81) bahwa pembelajaran konstruktivis bermedia $e$ learning efektif untuk meningkatkan penguasaan konsep SPLDV (Sistem Persamaan Linier Dua Variabel) siswa. Hasil penelitian lain yakni oleh Rudiyanto dan Waluya (2010: 33-44) didapatkan bahwa dengan model pembelajaran berbasis media $\mathrm{CD}$ interaktif dengan strategi konstruktivisme dapat membuat siswa memecahkan masalah volum benda putar secara mandiri dan kritis.

\section{KESIMPULAN DAN SARAN}

Dari penjelasan hasil penelitian dan pembahasan di atas, dapat disimpulkan bahwa: a) penelitian ini telah berhasil menyelenggarakan pembelajaran bebasis teori belajar konstruktivistik, yakni pembelajaran berbantuan multimedia Powerpoint, greenboard, dan pensil-kertas, sehingga siswa dapat mengosntruksi sendiri rumus luas bangun datar; serta b) pembelajaran tersebut efektif secara signifikan untuk meningkatkan prestasi belajar siswa.

Untuk keperluan penelitian mendatang disarankan agar penelitian dikembangkan pada materi lain dan kelas lain. Agar teori belajar konstruktivistik berbantuan multimedia dapat dimanfaatkan lebih luas.

\section{DAFTAR PUSTAKA}

Arsyad, A. 2013. Media pembelajaran. Jakarta: Rajawali Pers.

Muijs, D., dan Reynolds, D. 2008. Effective teaching, teori dan praktek (terjemahan). Yogyakarta: Pustaka Pelajar.

Muttappallymyalil, J., dkk. 2016. "Evolution of technology in teaching: Blackboard and beyond in Medical Education". Nepal Journal of Epidemiology. $6 \quad$ (3). Online: https://www.ncbi.nlm.nih.gov/p mc/articles/PMC5082488/

Rudiyanto, M. S. dan S. B. Waluya. 2010. Pengembangan model pembelajaran matematika volum benda putar berbasis teknologi dengan strategi konstruktivisme Student Active Learning berbantuan CD interaktif kelas XII. Kreano. 1 (1). Online: https://journal.unnes.ac.id/nju/in dex.php/kreano/article/view/220/ $\underline{229}$.

Rusman. 2012. Belajar dan pembelajaran berbasis komputer. Bandung: Alfabeta. 
ISSN 2089-8703 (Print) Vol. 6, No. 3 (2017)

ISSN 2442-5419 (Online)

Sopamena, P. 2009. "Konstruktivisme dalam pendidikan matematika". Horizon Pendidikan. 4 (1). Online:

http://iainambon.ac.id/phocadow nload/Fatma_Sopamena/konstru ktivisme\%20dalam\%20pendidik an\%20matematika\%20jurnal.pdf

Sugiyono. 2011. Metode penelitian kuantitatif, kualitatif, dan $R \& D$. Bandung: Alfabeta.
Widiyasari, R. 2015. "Pengembangan pembelajaran matematika konstruktivis berbantuan $e$ learning untuk meningkatkan penguasaan konsep matematika pada materi SPLDV kelas VIII". Fibonacci. 1 (1). Online: https://jurnal.umj.ac.id/index.ph p/fbc/article/view/1630/1382. 